\title{
Bile Salt Malabsorption in Regional Ileitis, Ileal Resection, and Mannitol-Induced Diarrhea
}

\author{
Walter E. Menhoff and Fred Kern, Jr. \\ From the Division of Gastroenterology, Department of Medicine, University of \\ Colorado Medical Center, Denver, Colorado
}

A в S T R A C T Fecal bile salt excretion was studied in healthy volunteers, patients with regional ileitis, and patients with ileal resection. $10 \mu \mathrm{c}$ of carboxyl- ${ }^{14} \mathrm{C}$-cholic acid was given orally. Stools and urine were collected daily for 5-10 days, the bile salts extracted, and the radioactivity assayed. Urinary excretion was negligible. All patients with ileal resection excreted bile salts in the feces significantly faster than controls, and five of the six excreted $50 \%$ of the radioactivity within $24 \mathrm{hr}$. Their mean intestinal transit time was $5.6 \mathrm{hr}$ compared to $26 \mathrm{hr}$ for the controls. Two of the three patients with regional ileitis excreted bile salts almost as rapidly as patients with ileal resection. Vitamin $B_{12}$ absorption was also defective in those patients, but the intestinal transit time was not decreased.

To study the effect of rapid intestinal transit on bile salt excretion, four of the control subjects were given orally $1200 \mathrm{ml}$ of $10 \%$ mannitol for 7 days, and the labeled cholic acid excretion rate was again studied. The mean intestinal transit time was markedly shortened, mild steatorrhea developed, and the fecal bile salt excretion rate increased slightly.

It is concluded that ileal resection and ileal disease are major factors and rapid intestinal

This work was presented in part at the Annual Meeting of the American Gastroenterological Association, Gastroenterological Research Forum, Colorado Springs, Colo., 25 May 1967, and abstracted in Gastroenterology. 1967. 52: 1139.

Address requests for reprints to Dr. Fred Kern, Jr., University of Colorado Medical Center, 4200 E. Ninth Avenue, Denver, Colo. 80220.

Received for publication 31 August 1967 and in revised form 11 October 1967. transit is a minor factor in causing excessive fecal bile salt loss. The relevance of bile salt wastage to lipid malabsorption is unknown because of insufficient information about compensatory jejunal absorption, maximum rate of hepatic bile salt synthesis, and the minimum necessary intraluminal concentration of conjugated bile salt.

\section{INTRODUCTION}

In man and experimental animals, bile salts are actively absorbed from the ileum (1-3), return to the liver via the portal circulation, and are reexcreted in the bile in combination with newly synthesized bile salts from the liver. The total bile salt pool circulates probably about six times each day (4). Ileal reabsorption and recirculation, rather than hepatic synthesis, is the major factor in maintaining the bile salt pool in normal man. Normal ileal absorption of bile salts is so efficient that less than $5 \%$ of the bile salt pool is lost in the feces per cycle.

Increased fecal loss of bile salts in several patients with ileal resection has recently been reported (5-7). Austad et al. showed an increased rate of loss in a single patient with racliation ileitis (8). We have extended these observations to study fecal bile salt loss in additional patients with ileal resection, in patients with regional ileitis. and in normal subjects in whom rapid intestinal transit was produced by the oral administration of a poorly absorbed sugar.

\section{METHODS}

Seven healthy volunteers, three patients with recional enteritis, and six patients with ileal resection were investigated. The normal subjects were four male medical 
students and three young women. In all three patients with regional enteritis, the disease was limited to the distal ileum; the diagnosis was confirmed by laparotomy in each patient. One patient underwent ileal resection after the study, and the ileum showed histologic features typical of regional enteritis. The patients with ileal resection were studied 4 months to $5 \mathrm{yr}$ after surgery. The ileum had been resected in five patients because of small bowel obstruction and in one patient because of infarction. The ileocecal valve and at least $2 \mathrm{ft}$ of distal ileum were removed in each patient.

All patients were hospitalized on the clinical research ward; control subjects were studied as outpatients. Routine laboratory studies, $d$-xylose absorption, $72 \mathrm{hr}$ fecal fat excretion, serum carotene concentration, and intestinal transit time, measured by the dye, brilliant-blue with carboxymethycellulose (9), were determined in all subjects and patients before study. Radiographic examination of the small intestine, quantitative bacteriologic culture of jejunal contents, Schilling test (10), and small bowel mucosal biopsy were obtained in patients with ileitis and ileal resection.

$10 \mu \mathrm{c}$ of carboxyl- ${ }^{14} \mathrm{C}$-cholic acid (Nuclear-Chicago Corporation, Des Plaines, Ill.), $12.2 \mu \mathrm{c} / \mu$ mole in $1 \mathrm{ml}$ of $95 \%$ ethanol in a large gelatin capsule, was given by mouth before breakfast followed by $600 \mathrm{mg}$ of dessicated ox bile (Armour Pharmaceutical Co., Chicago, Ill., NF) and $240 \mathrm{ml}$ of milk and cream. Stools and urine were collected in 24-hr aliquots for a 7-10 day period and were frozen immediately. Labeled cholic acid was given intravenously to several patients in separate experiments. The route of administration of the bile salt did not affect its rate of fecal excretion.

Bile salts were extracted from the urine by the method of Weiner et al. (11), and the radioactivity was assayed in a liquid scintillation spectrometer as described below.

Fecal bile salts were extracted by a modification of the method of Grundy et al. (12). Stools were thawed, diluted with water, and homogenized with a paint can shaker. $2 \mathrm{~g}$ of the homogenate was added to $40 \mathrm{ml}$ of $2 \mathrm{~N}$ $\mathrm{NaOH}$ in $90 \%$ ethanol and heated to $121^{\circ} \mathrm{C}$ at 16 psi for $90 \mathrm{~min}$. After cooling, the mixture was acidified to $\mathrm{pH} 2$ and shaken with $75 \mathrm{ml}$ of chloroform: methanol $(2: 1)$. The chloroform phase was separated, and the aqueous phase washed twice with $50 \mathrm{ml}$ of chloroform. The pooled chloroform extract was reduced to dryness in a rotary evaporator, and the residue was redissolved in $95 \%$ ethanol. An aliquot was placed in a counting vial and dryed under nitrogen. $15 \mathrm{ml}$ of Bray's solution (13) was added to the counting vial, and the radioactivity was quantitated in a liquid scintillation spectrometer. At the beginning of each extraction, a known amount of labeled cholic acid was added to a duplicate stool sample as an internal standard, and the same extraction procedure was followed. The recovery of the added cholic acid consistently ranged from 97 to $100 \%$, confirming the efficiency of the extraction.

To evaluate the effect of rapid intestinal transit on bile salt absorption, four of the control subjects were admitted to the research ward for further study. Diarrhea and rapid intestinal transit were induced by the oral administration of $1200 \mathrm{ml}$ of $10 \%$ mannitol daily for 7 days (14). Each day, $400 \mathrm{ml}$ of the mannitol solution was taken approximately $1 \mathrm{hr}$ after every meal. This regimen produced four to six liquid bowel movements per day. After diarrhea had been established for 1-2 days, the bile salt excretion study was repeated. $10 \mu \mathrm{c}$ of cholic acid was given orally to each subject, the stools and urine were collected, and the bile salt radioactivity was determined as described above. Fecal fat excretion was measured throughout the experimental period, and intestinal transit time was determined frequently. Two subjects had mild lower abdominal cramping discomfort, but all of them maintained moderate physical activity and ate normal diets containing $100 \mathrm{~g}$ of fat per day.

A simplified single-compartment kinetic model was assumed for data analysis $(15,16)$. This model predicts a log-linear excretion pattern described by $y=\mathrm{e}^{-b t}$, where $y=1-F, F=$ cumulative fraction of administered bile salt excreted, $b=$ decay constant, and $t=$ time in days.

The decay constant, $b$, was calculated for each data set by the method of least squares using an IBM 7044 digital computer. In accordance with the prediction of the model, the data could best be described by a single exponential function as confirmed by standard regression techniques. The standard errors of the estimates show that the decay constants were determined with precision (Table I). The group means of the decay constants were compared by analysis of variances.

\section{RESULTS}

The results are summarized in Tables I and II and Fig. 1. Typical examples of the bile salt excretion data are shown in Fig. 2.

Controls. Laboratory studies were normal in the seven volunteers. Mean transit time was $26 \mathrm{hr}$ from mouth to anus, and mean fecal fat was 3.5 $\mathrm{g} / 24 \mathrm{hr}$ (normal $\leq 5.0 \mathrm{~g} / 24 \mathrm{hr}$ ). Control subjects excreted labeled bile salt more slowly than did any of the study groups; the mean decay constant was 0.126 days $^{-1}$. The time for one-half of the labeled bile salt to be excreted varied from 3.2 to 6.4 days, which is somewhat longer than noted by other investigators $(8,16)$ who measured the daily decrease in concentration of labeled bile salt in duodenal content, rather than fecal excretion of bile salt. The longer transit time might be explained by the assumption of two sub-pools of bile salts, a large and rapidly circulating pool in the small intestine, and a small, sluggish pool in the colon (17). Calculation of bile salt turnover rate from duodenal concentrations might reflect primarily the rapidly circulating pool, whereas measurement of bile salt fecal excretion reflects hoth pools. The relatively lengthy mouth to anus 
TABLE I

Normal Controls, Mannitol-Induced Diarrhea, Ileitis and Ileal Resection

\begin{tabular}{lccrcc}
\hline Patient & $\begin{array}{c}\text { Transit } \\
\text { time }\end{array}$ & $\begin{array}{c}\text { Fecal } \\
\text { fat }\end{array}$ & $\begin{array}{c}\text { Fecal } \\
\text { wt }\end{array}$ & $\begin{array}{c}\text { Cholic acid-14C } \\
\text { decay constant }\end{array}$ & SE* $^{*}$ \\
\hline Control & $h r$ & $g / 2+h r$ & $g / 24 h r$ & days $^{-1}$ & \\
C. D. & 30 & 4.2 & 103 & 0.0659 & 0.02 \\
J. S. & - & 3.5 & 85 & 0.0888 & 0.02 \\
B. S. & 26 & 1.4 & 92 & 0.0974 & 0.01 \\
S. R. & - & 2.9 & 175 & 0.1265 & 0.02 \\
H. I. & 23 & 2.6 & 112 & 0.1514 & 0.01 \\
R. B. & 22 & 3.1 & 134 & 0.1519 & 0.01 \\
B. R. & - & 3.4 & 127 & 0.2115 & 0.01 \\
& & & & & \\
Mean & 25 & 3.1 & 118 & 0.1276 &
\end{tabular}

Mannitol-induced diarrhea

$\begin{array}{lcrrrr}\text { C. D. } & 4.5-6 & 14.8 & 580 & 0.1679 & 0.01 \\ \text { B. S. } & 5 & 4.4 & 1496 & 0.2676 & 0.02 \\ \text { H. I. } & 2.5-6 & 6.1 & 898 & 0.3523 & 0.02 \\ \text { R. B. } & 2.5-6 & 7.6 & 1238 & 0.2227 & 0.02 \\ & & & & & \\ \text { Mean } & 4.6 & 8.3 & 1053 & 0.2526 \ddagger & \end{array}$

Ileitis

$\begin{array}{lcrrrr}\text { J. C. } & 18 & 3.5 & 297 & 0.5052 & 0.03 \\ \text { D. W. } & 26 & 17.5 & 625 & 0.5992 & 0.15 \\ \text { S. M. } & 8.5-9 & 2.8 & 260 & 0.1585 & 0.02\end{array}$

Ileal resection

$\begin{array}{lllrll}\text { E. H. } & 5.5 & 21 & 1260 & 0.4414 & 0.05 \\ \text { V. C. } & 4 & 48 & 1008 & 1.0076 & 0.27 \\ \text { E. W. } & 4-5 & 55 & 1817 & 1.2135 & 0.19 \\ \text { V. L. } & 5.5 & 21 & 665 & 1.6391 & 0.72 \\ \text { L. C. } & 6.5 & 41 & 1552 & 1.6994 & 1.19 \\ \text { E. B. } & 8 & 10.5 & 1445 & 2.5749 & 0.90 \\ & & & & & \\ \text { Mean } & 5.6 & 32.7 & 1291 & 1.42938 & \end{array}$

* Standard error of the estimate of the decay constant. $\ddagger$ Differs from controls, $P<0.01$.

§ Differs from controls, $P<0.001$.

transit time in control subjects supports this hypothesis. During most of the $26 \mathrm{hr}$ of intestinal transit, intestinal content, including bile salt, is retained in the colon.

Regional ileitis. In all three patients the jejunal mucosal biopsy and $d$-xylose excretion were normal, and jejunal contents aspirated $10-15 \mathrm{~cm}$ distal to the ligament of Treitz were sterile. In two patients there was decreased absorption of ${ }^{57} \mathrm{CO}$-labeled vitamin $\mathrm{B}_{12}$ with intrinsic factor, and a significant increase in the rate of bile salt ex- cretion compared to normal control subjects $(P<0.001)$. The decay constants were 0.505 and 0.599 days $^{-1}$, but only one of these two patients had steatorrhea $(17.5 \mathrm{~g} /$ day $)$. The third patient (S. M.), who had minimal involvement of the terminal ileum, had a normal Schilling test and a normal rate of bile salt excretion $\left(0.1585\right.$ days $\left.^{-1}\right)$. This patient had no steatorhrea or other evidence of malabsorption, but because of "skip areas" of disease in the small bowel, the mouth to anus transit time was shortened to 8-9.5 hr.

Ileal resection. Jejunal mucosal biopsy was normal in each patient. Jejunal cultures, $15 \mathrm{~cm}$ beyond the ligament of Treitz, grew less than 100,000 organisms $/ \mathrm{ml}$ in each patient. Absorption of ${ }^{57} \mathrm{CO}$-labeled vitamin $\mathrm{B}_{12}$ with intrinsic factor was abnormally low in five of six patients, and serum carotene was below $75 \mu \mathrm{g} / 100 \mathrm{ml}$ in these five patients. Watery diarrhea was characteristic of this group. The mean daily fecal weight was $1291 \mathrm{~g}$, mean fecal fat $32.7 \mathrm{~g}$, and mean transit time $5.6 \mathrm{hr}$. The longest intestinal transit time was $8 \mathrm{hr}$.
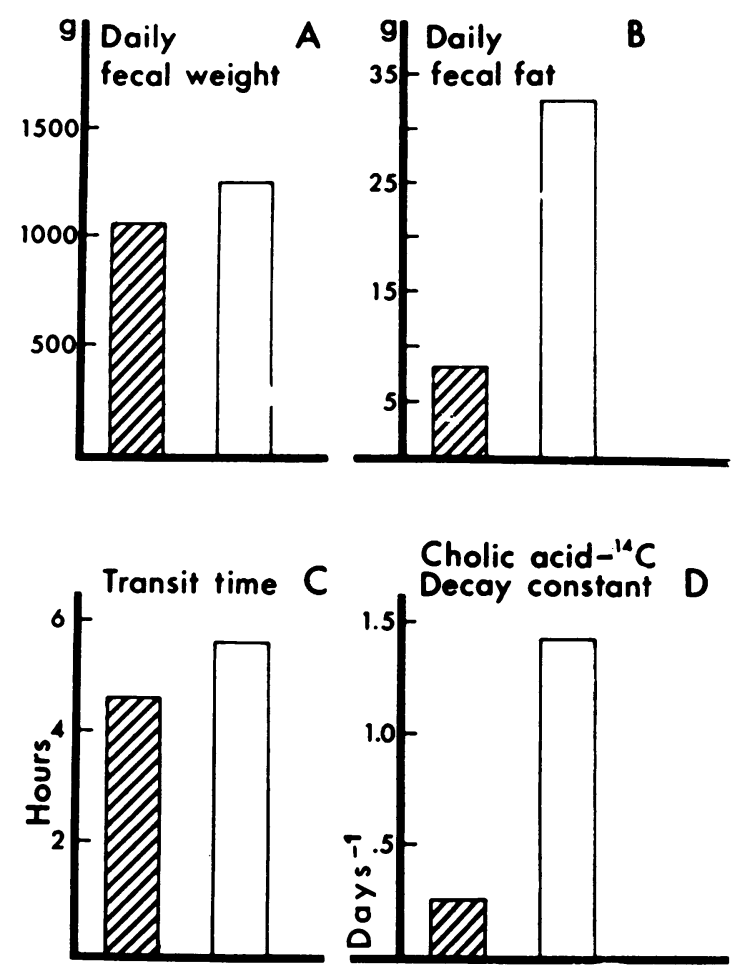

FIGURE 1 Comparison of the effect of mannitol-induced diarrhea (cross-hatched bar) with ileal resection (clear bar) on fecal weight (A), fecal fat (B), mouth to anus transit time (C) and cholic acid- ${ }^{14} \mathrm{C}$ decay constant (D). 
TABLE II

Studies in Patients with Ileitis and Ileal Resection

\begin{tabular}{|c|c|c|c|c|c|c|}
\hline Patient & $\begin{array}{c}\text { Serum } \\
\text { triglyceride* }\end{array}$ & $\begin{array}{c}\text { Serum } \\
\text { cholesterol } \neq\end{array}$ & $\begin{array}{c}\text { Serum } \\
\text { calcium } \S\end{array}$ & $\begin{array}{c}\text { Serum } \\
\text { carotene } \|\end{array}$ & $\begin{array}{l}d \text {-Xylose } \\
\text { excretion } \rrbracket\end{array}$ & $\begin{array}{l}\text { Schilling } \\
\text { test with I.F.** }\end{array}$ \\
\hline \multicolumn{7}{|l|}{ Ileitis } \\
\hline J. C. & - & 179 & 9.6 & 92 & 4.1 & 10 \\
\hline D. W. & 120 & 110 & 9.3 & 27 & 2.6 & 6 \\
\hline S. M. & 161 & 254 & 10.0 & 103 & 2.3 & 6.9 \\
\hline \multicolumn{7}{|c|}{ Ileal resection } \\
\hline E. H. & 56 & 65 & 4.4-9 & 20 & 2.0 & 3.1 \\
\hline V. C. & 59 & 122 & 8.7 & 10 & 3.0 & 3.7 \\
\hline E. W. & 67 & 148 & 8.8 & 12 & 1.7 & 4.2 \\
\hline E. B. & 59 & 72 & 9.2 & 120 & 5.0 & - \\
\hline L. C. & 100 & 71 & 10.0 & 55 & 4.6 & 5.8 \\
\hline V. L. & 83 & 138 & 8.9 & 55 & 5.0 & 4.5 \\
\hline
\end{tabular}

* Normal $70-140 \mathrm{mg} / 100 \mathrm{ml}$.

$\ddagger$ Normal $180-250 \mathrm{mg} / 100 \mathrm{ml}$.

§ Normal 9-10.5 mg/100 ml.

$\|$ Normal 75-200 $\mu \mathrm{g}$.

If Normal $5 \mathrm{~g}$.

${ }^{* *}$ Schilling test with intrinsic factor-normal; $7 \%$ excretion in $24 \mathrm{hr}$.

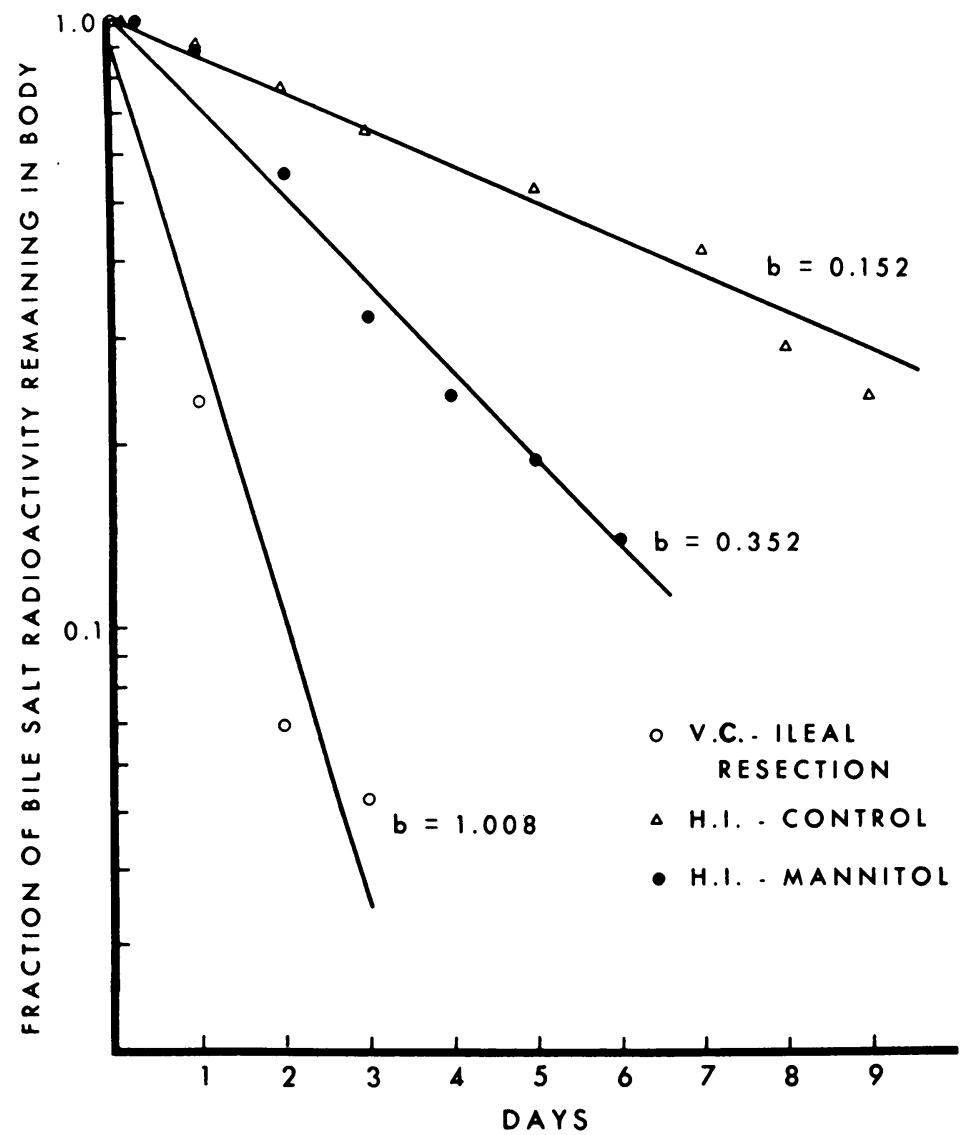

FIGURE 2 The decrease of radioactivity remaining in the body after oral administration of carboxyl-1 ${ }^{14} \mathrm{C}$-cholic acid in representative experiments. The solid lines represent computed values and $b$ represents the decay constant.

W. E. Meihoff and F. Kern, Jr. 
All patients excreted the labeled bile salt rapidly. The mean decay constant, 1.43 days $^{-1}$, was much greater in this group than in the control group $(P<0.001)$. There was poor correlation of decay constant with length of resection, steatorrhea, and transit time (Table I). For example, patient $E$. $H$. had the largest resection, the smallest decay constant, and only $21 \mathrm{~g}$ of fecal fat $/ 24 \mathrm{hr}$. Patient E. B. had a small resection, a decay constant of 2.5 days $^{-1}$, and $10.5 \mathrm{~g}$ of fecal fat $/ 24 \mathrm{hr}$. Five of the six patients excreted $50 \%$ or more of the labeled bile salt within $24 \mathrm{hr}$, a finding which is in agreement with the observations of others (15).

Mannitol-induced diarrhea. Marked alterations occurred in the four normal volunteers during the period of mannitol-induced diarrhea. Transit time decreased from a mean of $26 \mathrm{hr}$ before the study to $4.6 \mathrm{hr}$ during the period of diarrhea. Fecal fat excretion increased from a mean of 2.9 to $8.3 \mathrm{~g} / 24 \mathrm{hr}$. Fecal fat did not increase progressively during mannitol administration. The daily fecal volumes were similar to those of the ileal resection group. The rate of fecal bile salt loss was significantly increased from a control mean of 0.126 to a mean of 0.253 days $^{-1}$ during mannitol administration $(P<0.01)$. The effects of mannitol and ileal resection are compared in Fig. 1.

Because of the rapid mouth to anus transit time, it was assumed that transit through the ileum was also decreased. This assumption was confirmed by the administration of $400 \mathrm{ml}$ of $10 \%$ mannitol to two patients with an ileostomy. Mouth to ileostomy transit time, measured with brilliant-blue dye, decreased from a control of 3.5 and $4.5 \mathrm{hr}$ to 0.75 and $1.0 \mathrm{hr}$, respectively.

\section{DISCUSSION}

Although previous workers had suggested that the ileum was the major site of bile salt absorption $(1,18)$, Lack and Weiner conclusively demonstrated that active bile salt transport was limited to the ileum (19). The studies reported here confirm that resection or disease of the distal ileum is associated with increased fecal bile salt loss. Two of three patients with ileitis excreted bile salts nearly as rapidly as did patients with ileal resection. The third patient, with a normal Schilling test and no steatorrhea, excreted bile salts at a normal rate. Although the extent of ileal disease or resection is important, the functioning ileal surface area is only one of several important factors in bile salt loss and the associated steatorrhea. The relationship of small bowel transit time to absorption of fat, protein, and carbohydrates has not been thoroughly studied. Stahlgren in 1958 produced diarrhea, steatorrhea, and weight loss in dogs with ileal resection (20). The surgical placement of a short antiperistaltic segment to delay small bowel transit eliminated diarrhea, produced weight gain, and diminished steatorrhea. Decreased $d$-xylose absorption in postgastrectomy malabsorption and the carcinoid syndrome has been attributed to rapid intestinal transit (21). Rapid perfusion of the human jejunum with a $d$-xylose solution decreases the rate of its absorption (22).

In our study the oral administration of $10 \%$ mannitol to normal subjects decreased small bowel transit time and increased the rate of bile salt excretion. It is important to note, as emphasized in Fig. 1, that rapid transit alone was not a major cause of either rapid bile salt excretion or steatorrhea in these normal subjects. The transit times and fecal volumes produced by mannitol were essentially the same as those accompanying ileal resection, but the defects in bile salt and fat absorption were not nearly as great as those occurring with ileal resection. The mean bile salt decay constant in the patients with ileal resection was 11 times the control, while in the subjects with mannitol-induced diarrhea it was only twice the control. It is therefore clear that the amount of healthy ileal mucosa present is the most important factor in bile salt absorption.

Mannitol is poorly absorbed from the gastroinestinal tract. Diarrhea is produced by the osmotic effect of the unabsorbed sugar. Hindle and Code showed that only about $20 \%$ of an administered dose is absorbed by the rat intestine in a $1 \mathrm{hr}$ period (23), but there have been no similar studies in man. Recent evidence suggests that hypertonic mannitol placed in isolated rat jejunal loops can produce structural damage to the epithelial cell and decrease glucose absorption (24). In our subjects the mannitol was probably isotonic, or nearly isotonic, when it left the stomach, but the possibility of hypertonic ileal content, due to bacterial decomposition of the sugar and damage to the ileal mucosa, cannot definitely be excluded. Since 
the rate of fecal fat and bile salt excretion did not increase progressively during the period of mannitol administration, it is more likely that rapid transit alone was the major cause of both fat and bile salt malabsorption. The dilution of the bile salt in a large volume in the ileal lumen and hence its relative unavailability to the mucosa probably added to the effect of rapid transit. Although the steatorrhea probably resulted from rapid passage of triglycerides through the intestine, there is a possibility that bile salt depletion played some role.

Conjugated bile salts have important functions in the digestion and absorption of lipids, functions which have recently been reviewed $(25,26)$. These bile salts stimulate hydrolysis of triglyceride by pancreatic lipase, and they maintain the resultant fatty acid and monoglyceride in micellar solution, which is necessary for absorption. The intracellular conversion of absorbed lipids to triglycerides and their excretion in chylomicrons may also be stimulated by the presence of bile salts (27), but this hypothesis has been seriously questioned (28). The absorption of cholesterol and vitamin A depends upon adequate bile salt concentration $(29,30)$.

Despite these important actions, the practical significance of excessive bile salt loss in patients with ileal resection or disease is not known at this time. Impaired absorption of fats occurs in both experimental animals and patients with external biliary fistulae. Fat malabsorption, however, is often less striking than anticipated (31). To assess the significance of interruption of the enterohepatic bile salt cycle, both the capacity of the normal liver to synthesize bile salts in response to excess bile salt excretion and the minimal effective bile salt pool must be known. It has been estimated that the bile fistula rat can increase the rate of bile salt synthesis about 10 times (32), but such information is not available for man. Austad et al. reported a decrease in size of the taurocholate pool in their patient with ileal resection, but they did not measure the other bile salts (8).

Active ileal transport of bile salts is not the only mechanism by which bile salts are returned to the enterohepatic circulation. Significant absorption of unconjugated bile acids by passive diffusion occurs in the rat (33) and human jejunum (34). Hislop et al. found that glycine conjugates can also be absorbed by the human jejunum, probably by diffusion (34). It is possible that diffusion of both conjugated and unconjugated bile salts across jejunal mucosa is greater than normal in patients with ileal disease or resection for two reasons: (a) there might be a compensatory increase in synthesis of the more easily absorbed glycine conjugates; and $(b)$ in many patients with resection of the ileum and the ileocecal valve there is free access of bacteria to the proximal small intestine. Since some bacteria can deconjugate bile salts (35), the prompt jejunal absorption of the free bile salts and their return to the liver could contribute toward maintaining a normal bile salt pool. Furthermore, the number of absorptive cells in the human jejunum can increase after ileal resection (36), which might lead to a proportionate increase in jejunal absorption.

The critical intraluminal bile salt concentration necessary for adequate fat absorption has not been established. In two patients with ileal resection, Hofmann and Grundy, and Hardison and Rosenberg found a decrease in the micellar phase of jejunal lipids, which returned toward normal after the administration of bile salts $(5,6)$. These important measurements are needed in many patients to assess the actual importance of fecal bile salt loss in the malabsorption of triglycericles and other lipids.

\section{ACKNOWLEDGMENT}

The expert technical assistance of Miss Beverly Hope is gratefully acknowledged.

This work was supported by a grant from the Milheim Foundation of Denver, Colo., U. S. Public Health Service Training Grant in Gastroenterology, AM 5122, and the National Institutes of Health Clinical Research Unit of the University of Colorado (FR 00051).

\section{REFERENCES}

1. Baker, R. D., and G. W. Searle. 1960. Pile salt absorption at various levels of rat small intestine. Proc. Soc. Exptl. Biol. 105: 521.

2. Playoust, M. R., L. Lack, and I. M. Weiner. 1965. Effect of intestinal resection on bile salt absorption in dogs. Am. J. Physiol. 208: 363.

3. Borgström, B., G. Lundh, and A. F. Hofmann. 1963. The site of absorption of conjugated bile salts in man. Gastroenterology. 45 : 229.

4. Borgström, B., A. Dahlqvist, G. Lundh, and J. Sjövall. 1957. Studies of intestinal digestion and absorption in the human. J. Clin. Invest. 36: 1521.

5. Hofmann, A. F., and S. M. Grundy. 1965. Abnormal bile salt metabolism in a patient with extensive lower intestinal resection. Clin. Res. 13: 254. (Abstr.) 
6. Hardison, W. G. M., and I. H. Rosenberg. 1966. Malabsorption of bile salts as a cause of steatorrhea after ileal resection. Am. J. Clin. Nutr. 18: 312. (Abstr.)

7. Stanley, M., and B. Nemchausky. 1966. Steroidwasting enteropathy: Bile acid, cholesterol metabolism and treatment. Clin. Res. 14: 306. (Abstr.)

8. Austad, W. I., L. Lack, and M. P. Tyor. 1967. Importance of bile acids and of an intact distal small intestine for fat absorption. Gastroenterology. 52: 638

9. Lutwak, L., and B. T. Burton. 1964. Fecal dye markers in metabolic balance studies. The use of brilliant blue and methylcellulose for accurate separation of stool periods. Am. J. Clin. Nutr. 14: 109.

10. Schilling, R. F. 1953. Intrinsic factor studies. II. The effect of gastric juice on the urinary excretion of radioactivity after the oral administration of radioactive vitamin $\mathrm{B}_{12}$. J. Lab. Clin. Med. 42: 860.

11. Weiner, I. M., J. E. Glasser, and L. Lack. 1964. Renal excretion of bile acids: taurocholic, glycocholic, and cholic acids. Am. J. Physiol. $207: 964$.

12. Grundy, W. M., E. H. Ahrens, Jr., and T. A. Miettinen. 1965. Quantitative isolation and gas-liquid chromatographic analysis of total fecal bile acids. J. Lipid Res. 6: 397.

13. Bray, G. A. 1960. A simple efficient liquid scintillation for counting aqueous solutions in a liquid scintillation counter. Anal. Biochem. 1: 279.

14. Gertman, P. M., O. Gagnon, and F. L. Iber. 1966. Controlled diarrhea in the treatment of cirrhosis. J. Am. Wed. Assoc. 197: 257.

15. Hofmann, A. F. 1967. The syndrome of ileal disease and the broken enterohepatic circulation: cholerheic enteropathy. Gastrocnterology. 52: 752.

16. Linstedt, S. 1957. The turnover of cholic acid in man. Acta Physiol. Scand. 40: 1.

17. Lack, L. 1967. Role of the intestine during the enterohepatic circulation of bile salts. Gastroenterology. 52: 282.

18. Verzàr, F. 1936. Absorption from the intestine. Longmans, Green \& Co. Ltd., London. 294.

19. Lack, L., and I. M. Weiner. 1961. In vitro absorption of bile salts by the small intestine of rats and guinea pigs. Am. J. Physiol. 200: 313.

20. Stahlgren, L. H., G. Umana, R. Roy, and J. Donnelly. 1962. A study of intestinal absorption in dogs following massive small intestinal resection and insertion of an antiperistaltic segment. Ann. Surg. 156: 483.

21. Melmon, K. L., A. Sjoerdsma, J. A. Oates, and L. Laster. 1965. Treatment of malabsorption and diar- rhea of the carcinoid syndrome with methysergide. Gastroenterology. 48: 18.

22. Fordtran, J. S., K. H. Soergel, and F. J. Ingelfinger. 1962. Intestinal absorption of $d$-xylose in man. New Engl. J. Med. $267: 274$.

23. Hindle, W., and C. F. Code. 1962. Some differences between duodenal and ileal sorption. Am. J. Physiol. 203: 215 .

24. Kameda, H., T. Abei, S. Marsrallah, and F. L. Iber. The influence of hypertonic solutions of mannitol on intestinal absorption of glucose. Submitted for publication.

25. Senior, J. R. 1964. Intestinal absorption of fats. J. Lipid Res. 5: 495.

26. Hofmann, A. F., and D. M. Small. 1967.. Detergent properties of bile salts: correlation with physiological function. Ann. Rev. Med. 18: 333.

27. Dawson, A. M., and K. J. Isselbacher. 1960. Studies on lipid metabolism in the small intestine with observations on the role of bile salts. J. Clin. Invest. 39: 730 .

28. Pope, J. L., T. M. Parkinson, and J. A. Olson. 1966. Action of bile salts on the metabolism and transport of water-soluble nutrients by perfused rat jejunum in vitro. Biochim. Biophys. Acta. 130: 218.

29. Valhouny, G. V., C. R. Borja, and C. R. Treadwell. 1964. Absorption and esterification of micellar free and esterified cholesterol-4-C $\mathrm{C}^{14}$. Arch. Biochem. Biophys. 106: 440.

30. Olson, J. A. 1964. The effect of bile and bile salts on the uptake and cleavage of $\beta$-carotene into retinol ester (vitamin A ester) by intestinal slices. J. Lipid Res. 5: 402.

31. Kern, F., and B. Borgström. 1965. The effect of a conjugated bile salt on oleic acid absorption in the rat. Gastroenterology. 49: 623.

32. Bergstrom, S. 1962. Metabolism of bile acids. Federation Proc. $21: 28$.

33. Dietschy, J. M., H. S. Salomon, and M. D. Siperstein. 1966. Bile acid metabolism. I. Studies on the mechanism of intestinal transport. J. Clin. Invest. 45: 832.

34. Hislop, I. G., A. F. Hofmann, and L. J. Schoenfield. 1967. Determinants of the rate and site of bile acid absorption in man. J. Clin. Invest. 46: 1070. (Abstr.)

35. Tabaqchali, S., and C. C. Booth. 1966. Jejunal bacteriology and bile-salt metabolism in patients with intestinal malabsorption. Lancet. 2: 12.

36. Porus, R. L. 1965. Epithelial hyperplasia following massive small bowel resection in man. Gastroenterology. 48: 753 . 